now, with the exception of the entering cord, and (2) that the lens fibres between the main opacity and the surface of the lens, i.e., adult nucleus and cortex, are normal and transparent, there being not even riders of opacity from the cord in its passage through the lens.

\title{
GONOCOCCAL CONJUNCTIVITIS IN A SOCKET
}

\section{BY \\ J. H. Doggart \\ LONDON}

IN the literature concerning gonococcal conjunctivitis, I have found no record of this disease affecting a socket. Therefore it may be worth while to report the following case of a woman, aged 40 years, who recently attended St. George's Hospital.

This patient had lost her left eye ten years ago. She had been wearing an artificial eye without discomfort until the day before she first came to hospital, when the socket became painful, and began to discharge pus. On examination, there was diffuse redness, swelling, and tenderness around the left orbital margin. The discharge from the socket was profuse, yellow, and offensive.

Brawny enlargement and tenderness of the left preauricular lymphatic gland was noticed. Her temperature was raised $1^{\circ} \mathrm{F}$. Microscopy of a film of pus revealed gonococci.

Her only eye was protected by a Bullar's shield, and she was admitted to hospital. After two days' treatment with fomentations. frequent irrigation ( 1 in 4,000 solution of potassium permanganate) and argyrol drops, the pain, swelling, and discharge were much relieved, but some anxiety was felt for the eye, which, under the Bullar's shield, showed conjunctival injection and a slight mucopurulent secretion. This secretion, however, contained no organisms but staphylococci. Six days after admission to hospital, the socket ceased to discharge.

A swab was taken both before and after irrigation, but no more gonococci were found. There was no further trouble either in the eye or in the socket. Gynaecological examination showed that this patient was suffering from acute gonorrhoea. Gonococci were detected in a urethral smear of pus.

In this patient the right eye was microphthalmic and showed coarse lateral nystagmus; there was an extensive coloboma of the choroid in the usual position, involving the disc. Vision was reduced to $6 / 24$.

I wish to thank Mr. R. R. James for kindly allowing me to publish this case. The bacteriological investigations were the work of Dr. E. L. Hunt, bacteriologist to St. George's Hospital. 